\title{
Transport Defects of Rabbit Medullary Thick Ascending Limb Cells in Obstructive Nephropathy
}

\author{
Shang-Jyh Hwang, ** Mark Haas, " H. William Harris, Jr.," Patricio Silva," Subarrao Yalla, * Mary Rose Sullivan, * \\ Godwin Otuechere, * Michael Kashgarian, * and Mark L. Zeidel *ll \\ * Research Service, West Roxbury Department of Veterans Affairs Medical Center, West Roxbury, Massachusetts 02132, and Renal \\ Division, Brigham and Women’s Hospital, Boston, Massachusetts 02114; ${ }^{\ddagger}$ Nephrology Division, Kaohsiung Medical College, Kaohsiung, \\ Taiwan; ${ }^{\S}$ Department of Pathology, University of Chicago, Chicago, Illinois 60637; ** Department of Pathology, Yale University School \\ of Medicine, New Haven, Connecticut 06510; ${ }^{\$}$ Nephrology Division, New England Deaconess Hospital, "Renal Division, Children's \\ Hospital and Harvard Medical School, Boston, Massachusetts 02115
}

\begin{abstract}
To characterize the sodium transport defect responsible for salt wasting in obstructive nephropathy, the major sodium transporters in the medullary thick ascending limb (mTAL), the apical $\mathrm{Na}-\mathrm{K}-2 \mathrm{Cl}$ cotransporter and the basolateral $\mathrm{Na}-\mathrm{K}$ ATPase, were studied in fresh suspensions of mTAL cells and outer medulla plasma membranes prepared from obstructed and untreated kidneys. Oxygen consumption $\left(\mathrm{QO}_{2}\right)$ studies in intact cells revealed marked reductions in the inhibitory effects of both furosemide and ouabain on $\mathrm{QO}_{2}$ in cells from obstructed, as compared with control animals, indicating a reduction in activities of both the $\mathrm{Na}-\mathrm{K}-2 \mathrm{Cl}$ cotransporter and the Na-K-ATPase. Saturable $\left[{ }^{3} \mathbf{H}\right]$ bumetanide binding was reduced in membranes isolated from obstructed kidneys, but the $\boldsymbol{K}_{\mathrm{d}}$ for $\left[{ }^{3} \mathrm{H}\right.$ ]bumetanide was unchanged, indicating a decrease in the number of functional luminal $\mathrm{Na}-\mathrm{K}-2 \mathrm{Cl}$ cotransporters in obstructed mTAL. Ouabain sensitive Na-K-ATPase activity in plasma membranes was also reduced, and immunoblots using specific monoclonal antibodies directed against the $\alpha$ and $\beta$ subunits of rabbit Na-K-ATPase showed decreased amounts of both subunits in outer medullas of obstructed kidney. A significant decrease in $\left[{ }^{3} \mathrm{H}\right]$ bumetanide binding was detected after $4 \mathrm{~h}$ of ureteral obstruction, whereas Na-K-ATPase activity at this time was still not different from control. We conclude that ureteral obstruction reduces the amounts of both luminal $\mathrm{Na}-\mathrm{K}$ $\mathbf{2 C l}$ cotransporter and basolateral Na-K-ATPase in mTAL of obstructed kidney and that these reductions contribute to the salt wasting observed after release of obstruction. (J. Clin. Invest. 1993. 91:21-28). Key words: medullary thick ascending limb - Na-K-ATPase • Na-K-2Cl cotransporter • obstructive nephropathy $\bullet$ ureteral obstruction.
\end{abstract}

\section{Introduction}

In both human and animal studies, obstructive nephropathy causes reduced glomerular filtration rate, impairment of tubular reabsorption of sodium and potassium, and reductions in

This work was presented in part at the Annual Meeting of the American Federation for Clinical Research, Baltimore, MD, 1-4 May 1992, and published in abstract form (1992. Clin. Res. 40:218A).

Address reprint requests to Dr. Zeidel, Renal Section, Medical Service, West Roxbury DVAMC, 1400 VFW Parkway, West Roxbury, MA 02132.

Received for publication 29 May 1992 and in revised form 22 July 1992.

The Journal of Clinical Investigation, Inc.

Volume 91, January 1993, 21-28 the ability to secrete acid and concentrate the urine $(1,2)$. Because these defects are fully expressed after $24 \mathrm{~h}$ of ureteral obstruction in experimental animals such as rabbits, this convenient model has been used to characterize the renal impairment of obstructive nephropathy $(1,2)$. The postobstructive diuresis and salt wasting observed upon release of obstruction may result from the accumulation of volume and osmotic substances during the obstruction (3), which stimulate the secretion of hormones such as atrial natriuretic peptide (4), and prostaglandin $\mathrm{E}_{2}(5)$, with inhibitory effects on tubular sodium reabsorption $(6,7)$. However, measurements in isolated perfused tubules from obstructed kidneys have demonstrated intrinsic defects in tubular sodium reabsorption, which likely contribute to salt wasting (8-10).

Previous micropuncture and microperfusion studies have shown that the tubular reabsorption of sodium in the medullary thick ascending limb of the loop of Henle (mTAL) ${ }^{1}$ is impaired in obstructive nephropathy $(8,9)$. Although defects in transport have been localized to mTAL (8), there is little information as to the mechanisms underlying these derangements in tubular function. These transport defects may be due to reduced numbers or function of transporters, failure of cells to maintain polarity of transporter location, or inability of the cells to provide adequate energy for energy-requiring steps of active transport. Electron microscopic studies reveal little or no change in mTAL ultrastructure in obstructed (11), as compared to control kidneys. Therefore, the transport defects in obstructive nephropathy are likely to be selective, and are not associated with global changes in cellular architecture. Because the mTAL not only reabsorbs a significant portion of filtered sodium but also contributes to the urine concentrating mechanism (12), alterations in the function of this segment likely play a significant role in postobstructive sodium and water wasting.

The present studies examined the activities and numbers of the two major mTAL sodium transport proteins, the apical $\mathrm{Na}-\mathrm{K}-2 \mathrm{Cl}$ cotransporter and the basolateral Na-K-ATPase, in obstructed and control rabbit kidneys. The results show a downregulation of both transporters, and suggest that initial downregulation of the apical cotransporter may lead to reduced expression of the basolateral $\mathrm{Na}-\mathrm{K}-\mathrm{ATPase}$.

\section{Methods}

Animal model. New Zealand white rabbits (1-2 kg) were anesthetized with $0.7 \mathrm{ml} / \mathrm{kg}$ ketamine/xylazine mixture intramuscularly followed by $1 \mathrm{ml}$ of $50 \mathrm{mg} / \mathrm{ml}$ pentobarbital before surgery. Through a midline

1. Abbreviation used in this paper: $\mathrm{mTAL}$, medullary thick ascending limb. 
abdominal incision the ureters were identified and ligated with 2-0 silk just above the ureterovesical junction, and then the peritoneum and the skin were sutured. Sham operated animals underwent an identical procedure except that the ureters were not handled or ligated. Because preliminary studies showed there was no difference between sham operated and unoperated animals, unoperated normal animals were used as controls. Each animal was allowed ad libitum access to fluids and food for the following $24 \mathrm{~h}$ and was then euthanized.

Preparation of $m T A L$ cells. Cells were isolated from the mTAL of the loop of Henle as described (13). As previously reported (14), anesthetized rabbits were decapitated and exsanguinated, and the kidneys removed and perfused via the renal artery with an ice-cold solution consisting of nonbicarbonate Ringer (containing [in $\mathrm{mM}$ ]: $130 \mathrm{NaCl}$, $5 \mathrm{KCl}, 1 \mathrm{NaHPO}_{4}, 1 \mathrm{CaCl}_{2}, 1 \mathrm{MgSO}_{4}, 10$ Hepes-Tris, $\mathrm{pH} 7.4$ ) diluted $1: 1$ with Joklik's minimum essential medium (MEM) containing $10 \%$ fetal bovine serum (FBS) and $0.2 \%$ collagenase until the effluent was clear of blood. The outer medullas were excised, minced, and incubated for $1 \mathrm{~h}$ at $37^{\circ} \mathrm{C}$ in continuously oxygenated MEM + FBS containing $0.2 \%$ collagenase in a shaking water bath. Two or three times during this incubation the tissues were aspirated through a wide-bore pipette to disrupt cell aggregates. Tubules were harvested by centrifugation at $50 \mathrm{~g}$ for $5 \mathrm{~min}$ and washed in MEM + FBS, then incubated in oxygenated MEM + FBS containing $0.25 \%$ trypsin at $25^{\circ} \mathrm{C}$ for $20 \mathrm{~min}$ with gentle mechanical agitation. At the end of the trypsin digest the tubules were sedimented by centrifugation at $750 \mathrm{~g}$ for $25 \mathrm{~s}$. Isolated cells remained in the supernatant. The cells were harvested by centrifugation at $300 \mathrm{~g}$ for $5 \mathrm{~min}$, resuspended in MEM, and kept on ice until three additional trypsin digests of the tubules were completed. After a final wash with MEM + FBS, the cells were filtered through a nylon mesh and layered over previously prepared Ficoll gradients. Ficoll was dissolved in nonbicarbonate Ringer, $\mathrm{pH} 7.4$, equilibrated with $100 \%$ $\mathrm{O}_{2}$. Gradients were constructed linearly from a concentration of $5 \%$ (wt/vol) to $43 \%$ ( wt / vol) Ficoll. After layering the cells, the gradients were centrifuged at $1,900 \mathrm{~g}$ for $45 \mathrm{~min}$. The gradients were then removed in 4-ml fractions. mTAL cells were found in fractions 9-12 at the lower, more dense end of the gradients. These fractions were removed and washed in nonbicarbonate Ringer, then centrifuged at $1,400 \mathrm{~g}$ for $15 \mathrm{~min}$. The cells were resuspended in the buffer and kept on ice until use for oxygen consumption experiments. Cells were used within $2 \mathrm{~h}$ of the completion of the preparative procedure. Phase-contrast microscopy and trypan blue exclusion were performed routinely to ascertain the identity and viability of cells; viability was $>90 \%$ and was similar for suspensions prepared from control and obstructed kidneys.

Preparation of plasma membranes. Excised outer medullae were immediately added to ice-cold sucrose-histidine buffer (containing [in $\mathrm{mM}$ ] 25 sucrose, 30 histidine, 1 EDTA, $\mathrm{pH} 7.2$, with the following added protease inhibitors: $300 \mu \mathrm{M}$ phenylmethylsulfonyl fluoride, 1.5 $\mu \mathrm{M}$ pepstatin, and $1.5 \mu \mathrm{M}$ leupeptin). After mincing, tissue was added to a glass homogenization vessel containing fresh sucrose-histidine and was homogenized using a tight-fitting Teflon pestle keeping the glass vessel immersed in ice. The homogenate was centrifuged successively at $1,000 \mathrm{~g}$ and $7,000 \mathrm{~g}$ for $15 \mathrm{~min}$, both at $0^{\circ} \mathrm{C}$. The pellets were discarded, and the 7,000- $g$ supernatant was centrifuged for $45 \mathrm{~min}$ at $47,000 \mathrm{~g}$ and $0^{\circ} \mathrm{C}$ to yield a crude plasma membrane pellet $(15,16)$. This pellet was resuspended in $1 \mathrm{ml}$ of fresh, ice-cold sucrose-histidine. Aliquots were stored at $-70^{\circ} \mathrm{C}$ until used in experiments for $\left[{ }^{3} \mathrm{H}\right]-$ bumetanide binding, Na-K-ATPase activity, and for immunoblots of Na-K-ATPase. Protein contents were determined by bicinchoninic acid (BCA) assay (Pierce Chemical Co., Rockford, Ill.)

Measurement of oxygen consumption $\left(\mathrm{QO}_{2}\right) \cdot \mathrm{QO}_{2}$ was measured as described (17), using miniature Clark-type polarographic electrodes in sealed, continuously stirred, water-jacketed custom-made $500-\mu l$ glass chambers at $37^{\circ} \mathrm{C}$. The incubation medium was nonbicarbonate Ringer, pH 7.4, containing $5 \mathrm{mM}$ glucose, $2 \mathrm{mM}$ acetate, and $10 \mathrm{mM}$ pyruvate. After a control period sufficient to establish a stable baseline, additions of agents were made in volumes $<1 \%$ of the volume of the chamber to eliminate potential dilution artifacts; addition of incuba- tion buffer alone did not alter $\mathrm{QO}_{2}$. The rate of $\mathrm{QO}_{2}$ was calculated from the slope of the recorded line by measuring its angle against the room air baseline and calculating its tangent. When the measurement of $\mathrm{QO}_{2}$ was ended, an aliquot of the cell suspension, still under constant stirring in the measuring chamber, was removed and its wet weight was determined by centrifugation in a tared microcentrifuge tube. To determine the effect of furosemide or ouabain, these agents were added and the new rate of $\mathrm{QO}_{2}$ measured. The difference between $\mathrm{QO}_{2}$ in the presence and absence of a given agent was calculated for each preparation; these differences (e.g., the furosemide-sensitive $\mathrm{QO}_{2}$ ) were averaged and are shown in Table I. Results were also expressed as percent inhibition of control $\mathrm{QO}_{2}$.

Measurement of plasma membrane $\left[{ }^{3} \mathrm{H}\right]$ bumetanide binding. Equilibrium binding of $\left[{ }^{3} \mathrm{H}\right]$ bumetanide was determined by filtration assay using cellulose ester filters (Gelman GN-6, Gelman Sciences, Inc., Ann Arbor, MI), as previously described $(15,16)$. Briefly, $15 \mu \mathrm{l}$ of membrane suspension (2-4 $\mathrm{mg}$ protein $/ \mathrm{ml}$ in sucrose/histidine) were added to $15 \mu \mathrm{l}$ of $\left[{ }^{3} \mathrm{H}\right.$ ] bumetanide-containing medium, and the sample was incubated for $30 \mathrm{~min}$ at $22^{\circ} \mathrm{C}$. Preliminary experiments showed that for the range of $\left[{ }^{3} \mathrm{H}\right]$ bumetanide concentrations employed, maximal binding was achieved within $20 \mathrm{~min}$ and remained constant over the ensuing $30 \mathrm{~min}$. After the 30 -min incubation, the sample was added to $10 \mathrm{ml}$ of ice-cold stopping solution ( $20 \mathrm{mM}$ Tris-Hepes plus $1 \mathrm{mM}$ $\mathrm{CaCl}_{2}, \mathrm{pH}$ 7.4) and filtered. The filters were then washed with three 5 -ml aliquots of ice-cold stopping solution, added to scintillation vials, allowed to air dry, and were counted with Optifluor (Packard Instruments, Inc., Downers Grove, IL). $\left[{ }^{3} \mathrm{H}\right]$ Bumetanide-binding incubations contained the following final ion concentrations (in $\mathrm{mM}$ ): $30 \mathrm{Na}$, $30 \mathrm{~K}, 8 \mathrm{Cl}$, and $26 \mathrm{SO}_{4}$. All $\left[{ }^{3} \mathrm{H}\right]$ bumetanide binding media were prepared with or without unlabeled bumetanide (final concentration, 25 $\mu \mathrm{M})$; final concentrations of $\left[{ }^{3} \mathrm{H}\right]$ bumetanide present are indicated in the individual tables and figures, or their legends. For all studies except concentration-response experiments (Fig. 1), the final concentrations of $\left[{ }^{3} \mathrm{H}\right]$ bumetanide present was $0.25 \mu \mathrm{M}$. Aliquots of each $\left[{ }^{3} \mathrm{H}\right]-$ bumetanide-containing medium were counted in every experiment.

Measurement of plasma membrane Na-K-ATPase activity. Ouabain-sensitive ATPase was measured using a modification of the method used by Garg et al. (18). The method couples the conversion of ATP to ADP to the oxidation of NADH to NAD ${ }^{+}$. The fluorescence of NADH was monitored in a Fluorimeter (excitation $345 \mathrm{~nm}$, emission $450 \mathrm{~nm}$, slit 2.5/7.5 nm; SLM Aminco, SLM Instruments, Inc., Urbana, IL). Frozen crude plasma membranes from outer medullas of normal and obstructed kidneys were thawed and diluted in standard assay buffer containing (in $\mathrm{mM}$ ): $100 \mathrm{NaCl}, 66.7 \mathrm{NH}_{4} \mathrm{Cl}, 50$ imidazole,

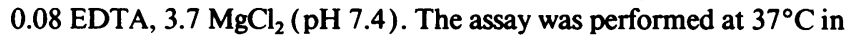
incubation buffer containing (in $\mathrm{mM}$ ): $0.027 \mathrm{NADH}, 0.5 \mathrm{Na}_{2} \mathrm{ATP}, 0.2$ phosphoenol pyruvate, as well as $4.7 \mathrm{U} / \mathrm{ml}$ pyruvate kinase and 6.7 $\mathrm{U} / \mathrm{ml}$ lactate dehydrogenase. After a stable basal fluorescence level was obtained, the reaction was started by adding an aliquot of plasma mem-

Table I. Oxygen Consumption in Medullary Thick Ascending Limb Cells from Obstructed and Control Kidneys

\begin{tabular}{lcc}
\hline \multicolumn{1}{c}{$\mathrm{OO}_{2}$} & Control $(n=5)$ & Obstructed $(n=6)$ \\
\hline & \multicolumn{2}{c}{$\mu$ mol/min $\cdot g$ wet wt } \\
Basal $\mathrm{QO}_{2}$, mean $\pm \mathrm{SE}$ & $1.55 \pm 0.14$ & $1.00 \pm 0.15^{*}$ \\
Furosemide-sensitive $\mathrm{QO}_{2}$ & $0.46 \pm 0.04$ & $0.08 \pm 0.02^{\S}$ \\
(\% inhibition of basal $\left.\mathrm{QO}_{2}\right)$ & $(30.5 \pm 2.6)$ & $\left(8.5 \pm 1.8^{5}\right)$ \\
Ouabain-sensitive $\mathrm{QO}_{2}$ & $0.75 \pm 0.05$ & $0.37 \pm 0.08^{\ddagger}$ \\
(\% inhibition of basal $\left.\mathrm{QO}_{2}\right)$ & $(49.7 \pm 3.1)$ & $\left(34.7 \pm 2.7^{*}\right)$ \\
Ouabain-insensitive $\mathrm{QO}_{2}$ & $0.79 \pm 0.11$ & $0.63 \pm 0.08$
\end{tabular}

${ }^{*} P<0.05,{ }^{\ddagger} P<0.01,{ }^{\S} P<0.001$ when compared with control kidneys. $\mathrm{QO}_{2}$; oxygen consumption rate. 
branes. Rates of fluorescence decay were linear, with $r$ value $>0.97$. After an initial rate of ATP degradation was obtained, $1 \mathrm{mM}$ ouabain was added, and the ouabain-insensitive activity was determined. Subtraction of ouabain-insensitive activity from total ATPase activity gave the ouabain-sensitive ATPase activity. Rates of ATPase activity were quantified by preparing standard curves in which known amounts of ADP were added to incubation mixture and the resulting decrease in NADH fluorescence recorded. In these standard curves, incremental addition of $5 \mathrm{nmol}$ ADP reduced fluorescence in a stepwise manner. The decrease in fluorescence was linear down to a level $<10 \%$ of the basal value; in assays, fluorescence was never permitted to fall to $<20 \%$ of the initial value (7).

Quantitation of Na-K-ATPase subunits by immunoblots. The plasma membrane preparations of outer medullas of obstructed and control kidneys were incubated with denaturing buffer (20\% SDS) at a ratio of 2:1 ( $\mathrm{vol} / \mathrm{vol})$. The protein contents were determined (Pierce BCA assay). $60 \mu \mathrm{g}$ of protein from each sample were subjected to SDSPAGE, then electrophoretically transferred to nitrocellulose membranes. These membranes were removed from the transfer apparatus and either stained with $0.1 \%$ amido black or blots were washed in $0.1 \%$ Tween-PBS, and incubated at $37^{\circ} \mathrm{C}$ in $3 \%$ gelatin for $1 \mathrm{~h}$ to block nonspecific binding. The blocked membrane was then incubated with monoclonal antibodies (19) against $\alpha$ or $\beta$ subunits of the Na-KATPase in $0.1 \%$ Tween-PBS for $1 \mathrm{~h}$. After washing with Tween-PBS the membrane was incubated at room temperature with alkaline phosphatase conjugated secondary antibody (Promega Corp., Madison, WI) for $30 \mathrm{~min}$. The membrane was washed and rinsed with alkaline phos-

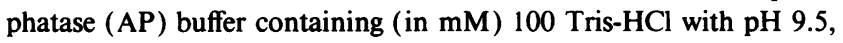
$100 \mathrm{NaCl}$, and $5 \mathrm{MgCl}_{2}$, then reacted with NBT-BCIP (Promega Corp.) in AP buffer until satisfactory coloration. The intensity of color was quantitated by transmission densitometry (20).

Materials. Collagenase was obtained from Worthington Biomedical Corp., Freehold, NJ; Ficoll was obtained from Pharmacia Fine Chemicals, Piscataway, NJ;. Joklik's minimal essential medium was obtained from Gibco, Grand Island NY; bicinchoninic acid protein assay was purchased from Pierce Chemical Co.; $\left[{ }^{3} \mathrm{H}\right]$ bumetanide was synthesized and purified by high performance liquid chromatography as previously described (15); the specific activity of the purified final product was $17.8 \mathrm{Ci} / \mathrm{mmol}$. Monoclonal antibodies directed against the $\alpha$ and $\beta$ subunits of the Na-K-ATPase were raised as described (19). All other reagents were obtained from Sigma Chemical Co., St. Louis, MO, and were of analytical grade.

Statistics. Samples were assayed in duplicate or triplicate. Data are expressed as mean \pm SEM. A single $n$ represents a cell suspension or membrane preparation. Each suspension or preparation was prepared from two or more animals and each animal contributed to one preparation. The differences in results between groups were tested by Student's $t$ test. Differences were considered statistically significant when the $P$ value was $<0.05$.

\section{Results}

The basal rate of $\mathrm{QO}_{2}$ in control was $1.55 \pm 0.13 \mu \mathrm{mol} / \mathrm{min} \cdot \mathrm{g}$ wet wt $(n=6)$, somewhat lower than the value previously reported for rabbit mTAL cell suspensions (14); this difference is likely due to differences in chamber volume and electrodes used (M. L. Zeidel, unpublished observations). However, the rate of basal $\mathrm{QO}_{2}$ in mTAL cells from obstructed kidneys was significantly lower $(1.00 \pm 0.14 \mu \mathrm{mol} / \mathrm{min} \cdot \mathrm{g}$ wet $\mathrm{wt}, n=6, P$ $<0.05$ ) than that of controls, as shown in Table I. To determine whether activities of luminal $\mathrm{Na}-\mathrm{K}-2 \mathrm{Cl}$ cotransporter or basolateral Na-K-ATPase were diminished in intact cells, the effects of furosemide $\left(10^{-4} \mathrm{M}\right)$, an inhibitor of the cotransporter, and ouabain $\left(10^{-4} \mathrm{M}\right)$, a Na-K-ATPase inhibitor, were studied in mTAL cells.

As shown in Table $\mathrm{I}$, the reduction in $\mathrm{QO}_{2}$ produced by furosemide in mTAL cells of obstructed kidneys was much smaller than the reduction observed in controls, suggesting a loss of $\mathrm{Na}-\mathrm{K}-2 \mathrm{Cl}$ cotransporter function. Indeed, the furosemide-sensitive $\mathrm{QO}_{2}$ in cells from obstructed kidneys was more than fivefold lower than the furosemide-sensitive $\mathrm{QO}_{2}$ in cells from control kidneys. The inhibitory effect of ouabain on $\mathrm{QO}_{2}$ was also strikingly reduced in mTAL cells from obstructed kidneys compared to controls, (Table I) indicating a decrease in Na-K-ATPase dependent oxygen consumption in mTAL cells of obstructed kidneys. By contrast, the ouabain-insensitive $\mathrm{QO}_{2}$ was not significantly reduced in obstructed kidneys, indicating that the fall in basal $\mathrm{QO}_{2}$ was confined to the transport-dependent portion of $\mathrm{QO}_{2}$.

Because the reduced inhibitory effect of furosemide on $\mathrm{QO}_{2}$ suggested reduced activity of the $\mathrm{Na}-\mathrm{K}-2 \mathrm{Cl}$ cotransporter in intact mTAL cells of obstructed kidneys, we used $\left[{ }^{3} \mathrm{H}\right]-$ bumetanide binding to determine whether this reduced activity corresponded to diminished numbers of cotransport sites in the mTAL. Fig. 1 illustrates $\left[{ }^{3} \mathrm{H}\right]$ bumetanide binding to plasma membranes isolated from the outer medulla of kidneys from a representative control (upper panel) and obstructed (middle panel) rabbit, as a function of $\left[{ }^{3} \mathrm{H}\right]$ bumetanide concentration. Saturable binding is determined as the difference in binding in the presence and absence of excess ( $25 \mu \mathrm{M})$ unlabeled bumetanide. Significant differences in saturable $\left[{ }^{3} \mathrm{H}\right]-$ bumetanide binding (at $0.25 \mu \mathrm{M}\left[{ }^{3} \mathrm{H}\right.$ ] bumetanide) to outer medullary plasma membranes were noted between six control and six 24-h obstructed rabbits as shown in Table II. For three control and three obstructed animals, complete concentrationresponse studies for $\left[{ }^{3} \mathrm{H}\right.$ ] bumetanide binding (as in Fig. 1, upper and middle panels) were performed. Plotting this data in the form of Scatchard plots (as is done for the representative control and obstructed rabbits in Fig. 1, lower panel) revealed a single class of binding sites with $B_{\max }$ of $14.2 \pm 1.4 \mathrm{pmol} / \mathrm{mg}$ protein. The $B_{\max }$ in outer medullary plasma membranes from 24-h obstructed kidneys was less than half that of the controls. By contrast, $K_{\mathrm{d}}$ was similar in membranes from control and obstructed kidneys (Table II). These results suggest a decrease in the number of $\mathrm{Na}-\mathrm{K}-2 \mathrm{Cl}$ cotransporters expressed in outer medullary plasma membranes of 24-h obstructed kidneys.

The plasma membrane Na-K-ATPase activity of outer medullary membranes was determined by the rate of ATP conversion to ADP in the absence and presence of ouabain, by linking the conversion of fluorescent NADH to nonfluorescent NAD to the appearance of ADP (Fig. 2). The ouabain-sensitive NaK-ATPase activity was significantly lower in outer medullary membranes of obstructed kidneys compared to controls $(220.6 \pm 29.2, n=10$, vs. $370.1 \pm 33.3 \mathrm{nmol}$ ATP degradation/ $\mathrm{min} / \mathrm{mg}$ protein, $n=9, P<0.005)$. Since the Na-K-ATPase activity from mTAL cells represents the major portion of outer medullary Na-K-ATPase activity, the results indicate a loss of Na-K-ATPase activity in mTAL cells of 24 -h obstructed kidneys.

To determine whether this loss of total Na-K-ATPase activity reflects a reduction in the number of pump subunits expressed in the plasma membrane, we performed immunoblots using specific antisera directed against rabbit $\alpha$ and $\beta$ subunits. Equal amounts of membrane protein from control $(n=4)$ and 24-h obstructed ( $n=4)$ kidneys were subjected to SDS-PAGE, and they showed a similar pattern of protein bands on amido black-stained gels (Fig. 3, left panel). However, immunoblots with antibodies against $\alpha$ and $\beta$ subunits of the Na-K-ATPase 

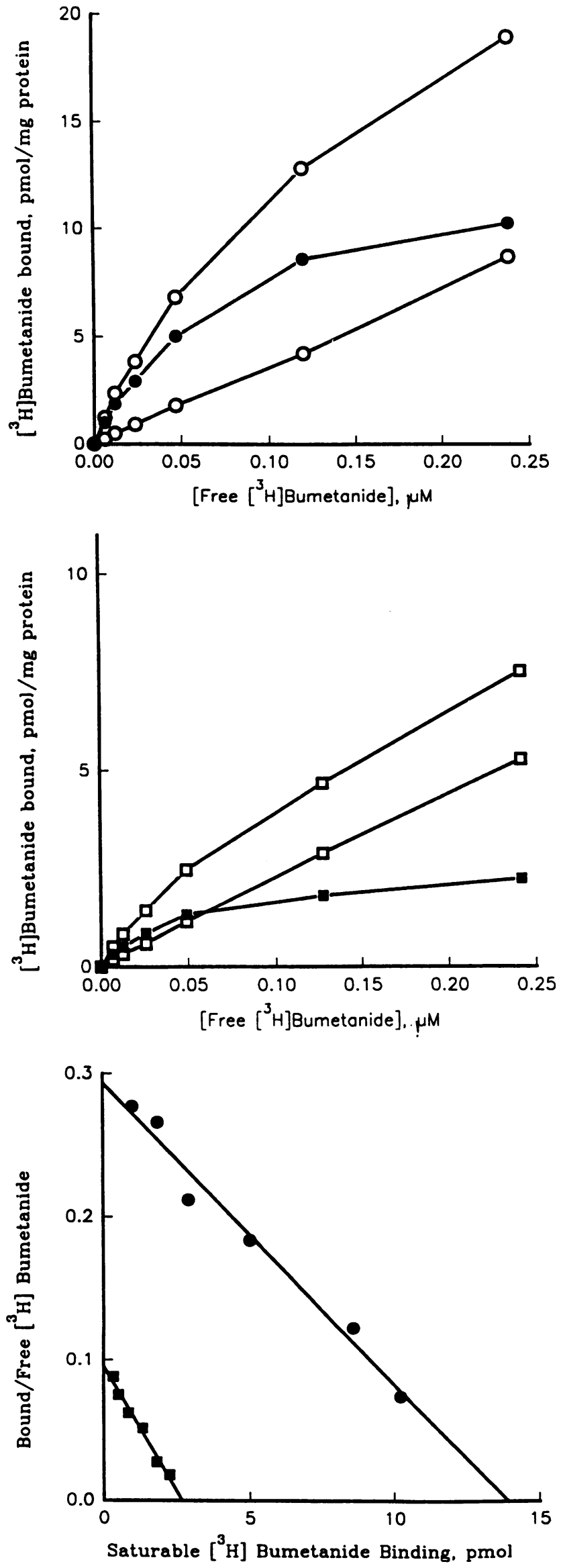

Table II. $\left[{ }^{3}\right.$ H]Bumetanide Binding in Outer Medulla Plasma Membranes of Obstructed and Control Kidneys

\begin{tabular}{lccc}
\hline & $\begin{array}{c}0.25 \mu \mathrm{M} \\
\text { bumetanide }\end{array}$ & $B_{\max }$ & $K_{\mathrm{d}}$ \\
\hline & $\begin{array}{c}\text { pmol/mg protein } \\
(n=6)\end{array}$ & $\begin{array}{c}\text { pmol } / m g \\
\text { protein }(n=3)\end{array}$ & $\begin{array}{c}\mu M \\
(n=3)\end{array}$ \\
Control & $7.99 \pm 0.86$ & $14.41 \pm 1.24$ & $0.10 \pm 0.03$ \\
Obstructed & $3.48 \pm 0.74^{*}$ & $4.71 \pm 1.94^{*}$ & $0.09 \pm 0.02$ \\
\hline
\end{tabular}

Values are mean $\pm \mathrm{SE} ;{ }^{*} P<0.005$ compared to control.

(Fig. 3, middle and right panels) revealed a striking decrease in both pump subunits in membranes from obstructed, as compared to control kidneys. The presence of multiple bands in the immunoblots for $\alpha$ subunit likely represents proteolysis of the subunit in the membrane preparation. Previous studies in rabbit kidney cortex using the same antibody and a slightly different protein preservation protocol have demonstrated 1-2 bands, tightly clustered around $110 \mathrm{kD}$. The immunoblot obtained for the $\beta$ subunit resembles closely that obtained in rabbit cortex in these same previous studies (M. Kashgarian, unpublished observations).

Since previous studies in both mTAL and cortical collecting duct have demonstrated that chronic inhibition of apical sodium entry pathways can reduce Na-K-ATPase activity (2123), we examined the time course of the decreases in apical $\mathrm{Na}-\mathrm{K}-2 \mathrm{Cl}$ cotransporters and in basolateral Na-K-ATPase using assays of plasma membrane $\left[{ }^{3} \mathrm{H}\right]$ bumetanide binding and ouabain-sensitive ATPase, respectively. Fig. 4 shows the time sequence of changes in $\left[{ }^{3} \mathrm{H}\right]$ bumetanide binding ( upper panel) and the Na-K-ATPase activity (lower panel) in outer medullary plasma membranes isolated from kidneys of control and 4-, 12-, and 24-h obstructed rabbits. Progressive decreases of both saturable $\left[{ }^{3} \mathrm{H}\right]$ bumetanide binding and Na-K-ATPase activity were noted throughout the first $24 \mathrm{~h}$ of obstruction. A significant decrease in $\left[{ }^{3} \mathrm{H}\right]$ bumetanide binding was also noted between the control and $4 \mathrm{~h}$ obstructed groups $(7.99 \pm 0.86, n$ $=6$ vs. $5.20 \pm 0.56 \mathrm{pmol} / \mathrm{mg}$ protein, $n=5, P<0.05$ ). However, there was no significant difference in Na-K-ATPase between control and 4-h obstructed groups, indicating that the decrease in $\mathrm{Na}-\mathrm{K}-2 \mathrm{Cl}$ cotransporter precedes the decrease in Na-K-ATPase activity.

Figure 1. $\left[{ }^{3} \mathrm{H}\right]$ bumetanide binding to outer medullary plasma membranes isolated from obstructed and control kidneys. Upper two panels depict binding as a function of free $\left[{ }^{3} \mathrm{H}\right]$ bumetanide concentration (range $0.006-0.250 \mu \mathrm{M}$ ) in the presence and absence of $25 \mu \mathrm{M}$ unlabeled bumetanide (open symbols) and saturable binding (filled symbols) to membranes from representative control (upper panel) and $24 \mathrm{~h}$ obstructed (middle panel) kidneys. Saturable binding at each $\left[{ }^{3} \mathrm{H}\right]$ bumetanide concentration is calculated as the difference in binding in the absence and presence of unlabeled bumetanide. Each data point in upper and middle panel represents the mean of triplicate binding determinations $\pm \operatorname{SE}(n=3)$. In lower panel, saturable binding data from upper panel (control, circles) and middle panel (obstructed, squares) is replotted in the form of a Scatchard plot. Decrease of $B_{\max }$ ( $x$-intercept) but no change of $K_{\mathrm{d}}(-1 /$ slope $)$ is noted in outer medullas of obstructed kidneys. 

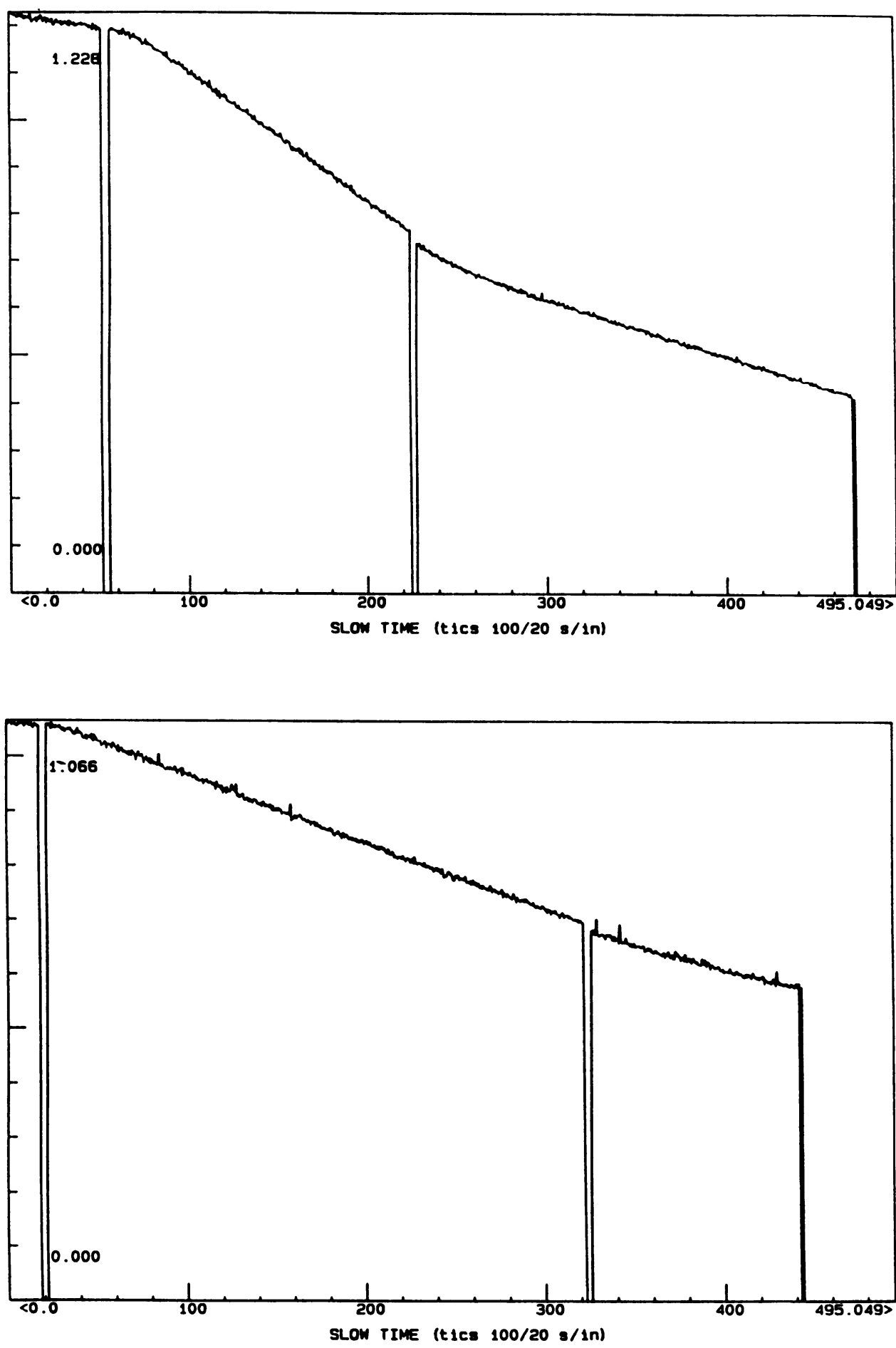

Figure 2. NADH fluorescence tracing in measurement of Na-K-ATPase activity in outer medullary plasma membranes from control (upper panel) and obstructed (lower panel) kidneys. The assay was performed at $37^{\circ} \mathrm{C}$ in standard assay buffer containing (in $\mathrm{mM}$ ) 100 $\mathrm{NaCl}, 66.7 \mathrm{NH}_{4} \mathrm{Cl}, 50$ Imidazole, 0.08 EDTA, $3.7 \mathrm{MgCl}_{2}, 0.027$ NADH, $0.5 \mathrm{Na}_{2} \mathrm{ATP}, 0.2$ phosphoenol pyruvate, $4.7 \mathrm{U} / \mathrm{ml}$ pyruvate kinase and $6.7 \mathrm{U} / \mathrm{ml}$ lactate dehydrogenase, $\mathrm{pH} 7.4$; after a stable basal fluorescence, the reaction was started by adding aliquot of plasma membranes. After obtaining an initial rate of ATP degradation, $1 \mathrm{mM}$ ouabain was added to determine the ouabain-insensitive activity. Rates of ATPase activity were quantified by decrease in NADH fluorescence after stepwise addition of $5 \mathrm{nmol}$ ADP to get the standard curve. Rates of fluorescence decay were linear, and the activity was calculated from the slope. Subtraction of ouabain-insensitive activity from total ATPase activity gave the ouabain-sensitive ATPase activity. The difference in slope before and after addition of ouabain was much less in obstructed kidneys.

\section{Discussion}

Obstructive nephropathy leads to salt wasting despite reduced glomerular filtration rate, indicating a defect in tubular reabsorption of sodium $(1,2)$. Qualitatively similar defects in renal function are present in short-term $(24 \mathrm{~h})$ obstructed as well as more chronically obstructed kidneys, suggesting that the mechanisms of dysfunction are similar in acutely and chronically obstructed kidneys $(1,2)$. The pathological changes in 24-h obstructed kidneys are relatively mild compared to ischemic renal lesions, so that mechanisms of dysfunction are not clouded by cell necrosis, inflammation or fibrosis $(11 ; \mathrm{S}$. J. Hwang and M. L. Zeidel, unpublished observations). In addition, functional studies of tubular segments from unilateral or bilateral obstructed kidneys show similar results $(8)$, indicating that similar defects occur in the obstructed kidney, whether or not the contralateral kidney is obstructed.

However, in bilateral ureteral obstruction, tubular transport defects are caused, in part by the accumulation of volume and solutes (3), leading to increased levels of natriuretic sub- 


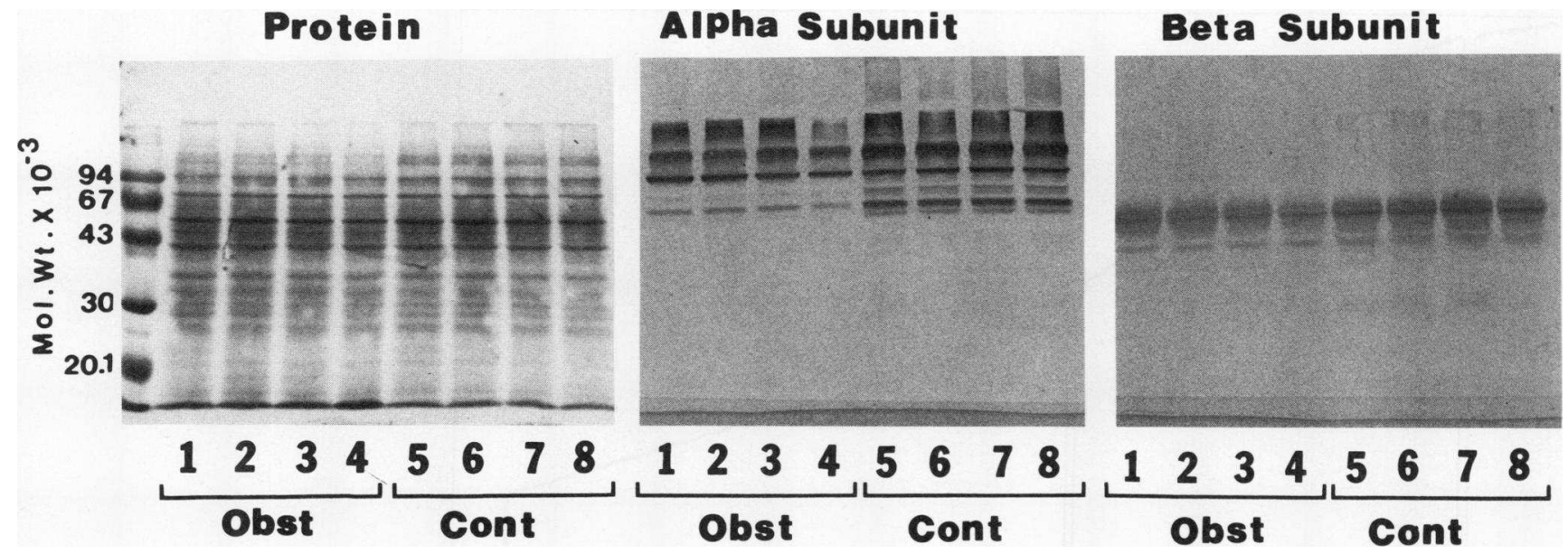

Figure 3. Immunoblots to $\alpha$ and $\beta$ subunits of Na-K-ATPase of outer medullary plasma membranes from obstructed and control kidneys. Left panel: $60 \mu \mathrm{g}$ of SDS denatured plasma membrane protein was applied to each PAGE lane. The distribution of protein in both obstructed (lanes $5-8$ ) and control (lanes 1-4) is similar with consistent differences observed in the 100-kD region of the gel. Middle panel: Immunoblot of duplicate proteins using monoclonal antibody to the $\alpha$ subunit of Na-K-ATPase. Right panel: Immunoblot of duplicate proteins using monoclonal antibody to the $\beta$ subunit of Na-K-ATPase.

stances such as atrial natriuretic peptide and renal prostaglan$\operatorname{din} E_{2}(4,5)$. In addition to these hormonal changes, alterations of tubular transport function in several nephron segments $(8,10,24,25)$, including the mTAL, are also responsible for salt wasting. Thus, isolated perfused $\mathrm{mTAL}$ from obstructed kidneys reabsorb $\mathrm{Cl}^{-}$less effectively than tubules from control kidneys ( 8 ). In addition, measurements of medullary tonicity have demonstrated medullary washout in obstructed kidneys, suggesting a defect in mTAL transport of solutes into the interstitium $(24,26)$.

Although deficient mTAL sodium transport contributes to salt wasting in obstruction, the specific mechanisms underlying this defect remain unclear. Previous studies have demonstrated a variety of alterations in outer medullary metabolic pathways, including reduced medullary oxygen consumption (27), reduced levels of adenine nucleotides (28), and diminished activities of glycolytic enzymes (27), as well as of Na-K-ATPase $(27,29,30)$, but it has been difficult to relate these alterations to specific transport defects. An attractive feature of obstructive nephropathy as a model for renal cell injury is the relatively mild ultrastructural damage observed in mTAL cells after $24 \mathrm{~h}$ of obstruction (11), a time when severe defects in tubular transport are well established. Thus, at $24 \mathrm{~h}$ of obstruction, transport defects can be studied in cells which have not developed the severe ultrastructural derangements observed in most models of ischemic renal damage.

The present studies demonstrate that intact mTAL cells prepared from obstructed kidneys have reduced transport-dependent $\mathrm{QO}_{2}$. By contrast, the level of transport-independent $\mathrm{QO}_{2}$ was not different in cells from obstructed and control kidneys (Table I). These results demonstrate that obstruction selectively reduces transport-dependent $\mathrm{QO}_{2}$. It is clear from the studies with furosemide and ouabain that both apical Na-K$2 \mathrm{Cl}$ cotransporter and basolateral $\mathrm{Na}-\mathrm{K}$-ATPase activities were reduced in intact cells obtained from obstructed kidneys.

At present, quantification of cotransporter sites is best studied by specific, saturable $\left[{ }^{3} \mathrm{H}\right]$ bumetanide binding ( 31 ). Saturable binding of $\left[{ }^{3} \mathrm{H}\right]$ bumetanide to the $\mathrm{Na}-\mathrm{K}-2 \mathrm{Cl}$ cotransporter directly parallels bumetanide inhibition of cotransport activity, both with respect to affinity and requirement for the simultaneous presence of $\mathrm{Na}^{+}, \mathrm{K}^{+}$, and $\mathrm{Cl}^{-}$ions (15, 31-33). The number of $\left[{ }^{3} \mathrm{H}\right]$ bumetanide binding sites on both intact cells (32, 34-36) and plasma membranes (33) has also been shown to vary proportionally with $\mathrm{Na}-\mathrm{K}-2 \mathrm{Cl}$ cotransport activity following exposure of cells to physiological stimuli or inhibitors of cotransport activity. This latter property of $\left[{ }^{3} \mathrm{H}\right]$ bumetanide binding indicates that the number of saturable $\left[{ }^{3} \mathrm{H}\right]-$ bumetanide binding sites provides a measure of the number of functional cotransporters in the plasma membrane.

Studies in plasma membranes isolated from control and obstructed kidneys revealed reduced levels of $\left[{ }^{3} \mathrm{H}\right]$ bumetanide binding after obstruction, but no change in the affinity of binding sites for $\left[{ }^{3} \mathrm{H}\right]$ bumetanide. These results confirm the evidence from $\mathrm{QO}_{2}$ studies of reduced cotransporter activity in obstructed kidneys, and suggest that the reduction in cotransporter activity observed in intact mTAL cells reflects reduced numbers of functional cotransporter proteins in the apical membranes of these cells in situ. The lack of effect of obstruction on the dissociation constant for $\left[{ }^{3} \mathrm{H}\right]$ bumetanide binding suggests that those cotransporter proteins that are present after obstruction might function normally. Defining the signals by which obstruction reduces the number of functional cotransporters will require the availability of specific antibody and cDNA probes for the cotransporter so that the regulation of cotransporter mRNA transcription and translation as well as post-translational intracellular transport and modification of cotransporter protein can be studied.

Basolateral Na-K-ATPase activity in intact mTAL cells was also reduced and this reduction was confirmed by the demonstration of reduced ouabain-sensitive ATPase activity as well as reduced $\alpha$ and $\beta$ subunit protein in membranes prepared from outer medullae of obstructed kidneys. Measurements of ouabain-sensitive ATPase in permeabilized membranes and of subunit proteins agreed well, and indicate that the reduction in Na-K-ATPase activity is due to reduced amounts of both subunits in membranes of obstructed kidneys. These results differ from those obtained by Brunskill et al. (37) in basolateral membranes obtained from the cortices of obstructed kidneys. 

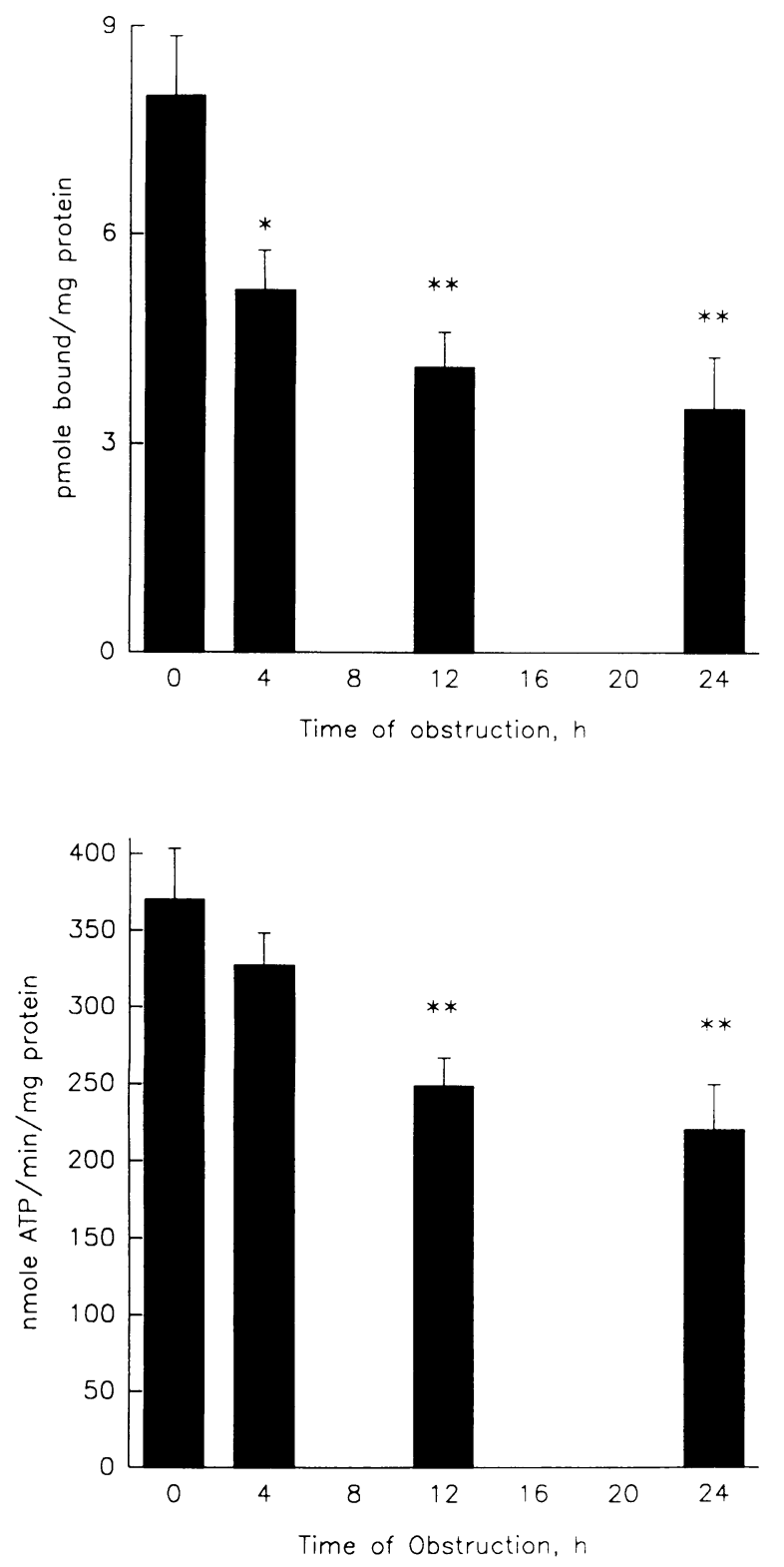

Figure 4. Time course study of $\left[{ }^{3} \mathrm{H}\right]$ bumetanide binding (upper panel) and $\mathrm{Na}-\mathrm{K}-\mathrm{ATPase}$ activity (lower panel) in outer medullas plasma membranes from control ( 0 time; upper, $n=6$; lower, $n$ $=9$ ), $4 \mathrm{~h}$ (both, $n=5$ ), $12 \mathrm{~h}$ (both, $n=6$ ) and $24 \mathrm{~h}$ (upper, $n$ $=6$; lower, $n=10$ ) obstructed kidneys. Data are expressed as mean \pm SE. ${ }^{*} P<0.05,{ }^{* *} P<0.005$ compared to control.

In this study, the amounts of pump subunits were not decreased in obstructed kidney membranes, and the loss of pump activity was attributed to changes in the composition and fluidity of basolateral membranes brought on by obstruction. These differences in results are likely due to the use of membranes from different nephron segments.

It is well known that obstruction markedly increases renal medullary $\mathrm{PGE}_{2}$ content ( 5 ) and that $\mathrm{PGE}_{2}$ stimulates natriuresis in the mTAL. Moreover, Campbell et al. (38) have recently shown that reducing $\mathrm{PGE}_{2}$ synthesis in obstructed kidneys partially restores cortical collecting duct water permeability. These results suggest that increased $\mathrm{PGE}_{2}$ generation in obstructed kidneys might participate in the apparent down-regulation of cotransporter activity which we have observed.

To explore the relationship between reduced cotransporter and pump numbers of mTAL apical and basolateral membranes, we examined the time course, during the development of obstruction, of the loss of apical and basolateral transporters. It appears from Fig. 4 that the loss of cotransporter precedes that of pump. Several studies in both mTAL and collecting duct have demonstrated that chronic reductions in apical sodium entry can diminish basolateral $\mathrm{Na} / \mathrm{K}$-ATPase activity in the presence of aldosterone stimulation (21-23). For example, in mTAL, Grossman and Hebert (21) demonstrated that mineralocorticoid-induced increases in pump activity could be prevented by chronic inhibition of the apical cotransporter using furosemide. Similarly, in collecting duct, chronic amiloride inhibition of apical sodium channels blocks mineralocorticoid stimulation of $\mathrm{Na} / \mathrm{K}$-ATPase $(22,23)$. By contrast, in the presence of normal aldosterone levels, reductions of $\mathrm{Na}^{+}$entry did not lower $\mathrm{Na} / \mathrm{K}$-ATPase activity below basal levels (23). Thus, our results show that obstruction reduces the number of functional apical Na-K-2Cl cotransporters, leading to chronic decreases in sodium entry into mTAL cells. The reduction in sodium entry caused by reduced apical Na-K-2Cl cotransporters and reduced $\mathrm{Na}^{+}$delivery to the mTAL during obstruction may contribute to reduced synthesis and deployment of Na-K-ATPase in the basolateral membrane.

The combined effect of these reductions in apical and basolateral sodium transport activities is to reduce active sodium reabsorption by the $\mathrm{mTAL}$. In that active sodium transport by the $\mathrm{mTAL}$ is also responsible for the generation of medullary hypertonicity, these transport defects may also contribute to the inability of obstructed kidneys to concentrate urine above the tonicity of plasma.

\section{Acknowledgments}

We thank Robert Fuhro, Christine Hosselet, and Donna McBrayer for outstanding technical assistance.

Dr. Zeidel is the recipient of Career Development and Merit Review Awards from the Department of Veterans Affairs. Drs. Haas and Harris are Established Investigators of the American Heart Association. These studies were also supported by National Institutes of Health Grants DK-43955 to Dr. Zeidel, DK-38774 to Dr. Harris, and DK17433 to Dr. Kashgarian, National Institute of Environmental Health Sciences grant ESO-3828 to Dr. Silva and by a grant-in-aid from the American Heart Association (Metropolitan Chicago Chapter) to Dr. Haas.

\section{References}

1. Yarger, W. E. 1991. Urinary tract obstruction. In The Kidney. B. M. Brenner and F. C. Rector, editors. W. B. Saunders Company, Philadelphia. 17681808 .

2. Klahr, S., and K. P. G. Harris. 1992. Obstructive uropathy. In The Kidney: Physiology and Pathophysiology. D. W. Seldin and G. Giebisch, editors. Raven Press, New York. 3327-3369.

3. Harris, R. H., and W. E. Yarger. 1975. The pathogenesis of postobstructive diuresis: The role of circulating natriuretic and diuretic factors, including urea. $J$. Clin. Invest. 56:880-887.

4. Purkerson, M. L., E. H. Blaine, T. J. Stokes, and S. Klahr. 1989. Role of atrial peptide in the natriuresis and diuresis that follows relief of obstruction in rat. Am. J. Physiol. 256:F583-F589.

5. Okegawa. T., P. E. Jonas, K. K. DeSchryver, A. Kawasaki, and P. Needleman. 1983. Metabolic and cellular alterations underlying the exaggerated renal prostaglandin and thromboxane synthesis in ureter obstruction in rabbits: inflammatory response involving fibroblasts and mononuclear cells. J. Clin. Invest 71:81-90. 
6. Zeidel, M. L., D. Kikeri, P. Silva, M. Burrowes, and B. M. Brenner. 1988. Atrial natriuretic peptides inhibit conductive sodium uptake by rabbit inner medullary collecting duct cells. J. Clin. Invest. 82:1067-1074.

7. Jabs, K., P. Silva, and M. L. Zeidel. 1989. Prostaglandin $\mathrm{E}_{2}$ inhibits Na-KATPase in rabbit inner medullary collecting duct cells. Am. J. Physiol. 257:F424F430.

8. Hanley, M. J., and K. Davidson. 1982. Isolated nephron segments from rabbit models of obstructive uropathy. J. Clin. Invest. 69:165-174.

9. Wilson, D. R. 1972. Micropuncture study of chronic obstructive nephropathy before and after release of obstruction. Kidney Int. 2:119-130.

10. Jaenike, J. R. 1972. The renal functional defect of postobstructive nephropathy: The effects of bilateral ureteral obstruction in the rat. J. Clin. Invest. 51:2999-3006.

11. Nagle, R. B., R. E. Bulger, R. E. Cutler, H. R. Jervis, and E. P. Benditt. 1973. Unilateral obstructive nephropathy in the rabbit: early morphologic, physiologic and histochemical changes. Lab. Invest. 28:456-467.

12. Greger, R. 1985. Ion transport mechanisms in thick ascending limb of Henle's loop of mammalian nephron. Physiol. Rev. 65:760-806.

13. Eveloff, J., E. Bayerdoerffer, P. Silva, and R. Kinne. 1981. NaCl transport in the thick ascending limb of Henle's loop: oxygen consumption studies in isolated cells. Pflügers Arch. Eur. J. Physiol. 389:263-270.

14. Lear, S., P. Silva, V. E. Kelley, and F. H. Epstein. 1990. Prostaglandin E2 inhibits oxygen consumption in rabbit medullary thick ascending limb. Am.J. Physiol. 258:F1372-F1378.

15. Forbush, B. III, and H. C. Palfrey. 1983. [ $\left.{ }^{3} \mathrm{H}\right]$ Bumetanide binding to membranes isolated from dog kidney outer medulla: relationship to the $\mathrm{Na}, \mathrm{K}, \mathrm{Cl}$ cotransport system. J. Biol. Chem. 258:11787-11792.

16. Haas, M., P. B. Dunham, and B. Forbush. 1991. [ $\left.{ }^{3} \mathrm{H}\right]$ Bumetanide binding to mouse kidney membranes: identification of corresponding membrane proteins. Am. J. Physiol. 260:C791-C804.

17. Zeidel, M. L., J. L. Seifter, S. Lear, B. M. Brenner, and P. Silva. 1986. Atrial peptides inhibit oxygen consumption in kidney medullary collecting duct cells. Am. J. Physiol. 251:F379-F383.

18. Garg, L. C., N. Narang, and C. S. Wingo. 1985. Glucocorticoid effects on Na/K-ATPase in rabbit nephron segments. Am. J. Physiol. 248:F487-F491.

19. Kashgarian, M., D. Biemesderfer, M. Caplan, and B. Forbush. 1985. Monoclonal antibody to $\mathrm{Na} / \mathrm{K}-\mathrm{ATPase}$ Immunocytochemical localization along nephron segments. Kidney Int. 28:899-913.

20. Towbin, H., T. Staehelin, and J. Gordon. 1979. Electrophoretic transfer of proteins from polyacrylamide gels to nitrocellulose sheets: procedure and some applications. Proc. Natl. Acad. Sci. USA 76:4350-4354.

21. Grossman, E. B., and S. C. Hebert. 1988. Modulation of Na-K-ATPase activity in mouse medullary thick ascending limb of Henle: effects of mineralocorticoids and sodium. J. Clin. Invest. 81:885-892.

22. Petty, K. J., J. P. Kokko, and D. Marver. 1981. Secondary effect of aldosterone on $\mathrm{Na}-\mathrm{K}-\mathrm{ATPase}$ activity in rabbit cortical collecting duct. J. Clin. Invest. 68:1514-1521.
23. O'Neil, R. G., and R. A. Hayhurst. 1985. Sodium-dependent modulation of the renal Na-K-ATPase: Influence of mineralocorticoids on the cortical collecting duct. J. Membr. Biol. 85:169-179.

24. Buerkert, J., D. Martin, M. Head, J. Prasad, and S. Klahr. 1978. Deep nephron function after release of acute unilateral ureteral obstruction in the young rat. J. Clin. Invest. 62:1228-1239.

25. Sonnenberg, H., and D. R. Wilson. 1976. The role of the medullary collecting ducts in postobstructive diuresis. J. Clin. Invest. 57:1564-1574.

26. Knox, W. H., J. A. Sax, D. R. Wilson, and A. K. Sen. 1977. Effect of osmolality on renal medullary $\mathrm{Na} / \mathrm{K} / \mathrm{ATPase}$ activity in the postobstructive kidney. Can. J. Physiol. Pharmacol. 55:1112-1115.

27. Klahr, S., S. J. Schwab, and T. J. Stokes. 1986. Metabolic adaptations of the nephron in renal disease. Kidney Int. 29:80-89.

28. Nito, H., C. Descoeudres, K. Kurokawa, and S. G. Massry. 1978. Effects of unilateral ureteral obstruction on renal cell metabolism and function. J. Lab. Clin. Med. 91:60-71.

29. Williams, R. D., D. D. Fanestil, and C. E. Blackard. 1976. Etiology of postobstructive diuresis: ouabain-sensitive adenosine triphosphatase deficit and elevated solute excretion in the postobstructed dog kidney. Invest. Urol. 14:148152.

30. Sabatini, S., and N. E. Kurtzman. 1990. Enzyme activity in obstructive nephropathy: Basis for salt wastage and the acidifying defect. Kidney Int. 37:7984.

31. Haas, M. 1989. Properties and diversity of (Na-K-Cl) cotransporters. Annu. Rev. Physiol. 51:443-457.

32. Haas, M., and B. Forbush III. 1986. [ $\left.{ }^{3} \mathrm{H}\right]$ bumetanide binding to duck red cells. Correlation with inhibition of $\mathrm{Na}, \mathrm{K}, 2 \mathrm{Cl}$ cotransport. J. Biol. Chem. 261:8434-8441.

33. Pewitt, E. B., R. S. Hegde, M. Haas, and H. C. Palfrey. 1990. The regulation of $\mathrm{Na} / \mathrm{K} / 2 \mathrm{Cl}$ cotransport and bumetanide binding in avian erythrocytes by protein phosphorylation and dephosphorylation. J. Biol. Chem. 265:2074720756.

34. O'Donnell, M. E. 1989. $\left[{ }^{3} \mathrm{H}\right]$ Bumetanide binding in vascular endothelial cells: Quantitation of Na-K-Cl cotransporters. J. Biol. Chem. 264:20326-20330.

35. Franklin, C. C., J. T. Turner, and H. D. Kim. 1989. Regulation of $\mathrm{Na} / \mathrm{K} /$ $\mathrm{Cl}$ cotransport and $\left[{ }^{3} \mathrm{H}\right.$ ] bumetanide binding site density by phorbol esters in HT29 cells. J. Biol. Chem. 264:6667-6673.

36. O'Neill, W. C., and J. D. Klein. 1992. Regulation of vascular endothelial cell volume by Na-K-2Cl cotransport. Am. J. Physiol. 262:C436-C444.

37. Brunskill, N., C. Hayes, J. Morrissey, and S. Klahr. 1991. Changes in lipid environment decrease $\mathrm{Na} / \mathrm{K}$-ATPase activity in obstructive nephropathy. Kidney Int. 39:843-849.

38. Campbell, H. T., E. Bello-Reuss, and S. Klahr. 1985. Hydraulic water permeability and transepithelial voltage in the isolated perfused rabbit cortical collecting tubule following acute unilateral ureteral obstruction. J. Clin. Invest. 75:219-225. 